\title{
Low-UWB directive antenna for Wireless Capsule Endoscopy localization
}

\author{
Chaïmaâ Kissi ${ }^{1}$, Mariella Särestöniemi ${ }^{2}$, Carlos Pomalaza-Raez ${ }^{3}$, Marko Sonkki ${ }^{2}$ \\ and Mohamed Nabil Srifi ${ }^{1}$ \\ ${ }^{1}$ Electronics and Telecommunication Systems Research Group, National School of Applied \\ Sciences (ENSA), Ibn Tofail University, Kenitra, Morocco. \\ ${ }^{2}$ Center for Wireless Communications, Faculty of Information Technology and Electrical En- \\ gineering, University of Oulu, Finland. \\ ${ }^{3}$ Department of Electrical and Computer Engineering, Purdue University, Fort Wayne, Indiana \\ 46805, USA.
}

\begin{abstract}
A novel UWB antenna working in the 805.15.6 Low-UWB region is proposed in this paper. The antenna is targeted for Wireless Capsule Endoscopy (WCE) localization. Simulation results show that the antenna performs well at 4 $\mathrm{GHz}$ with a $500 \mathrm{MHz}$ bandwidth which is complaint with the IEEE 802.15.6 standard for Body Area Networks (BAN). A preliminary study on the single antenna performance is presented first, followed by the introduction of the boxshaped cavity version of the antenna structure. Both types of antenna are directional with high gain. To investigate WCE applications, the cavity antenna in proximity of a multi-layer model emulating human body tissues properties at 4 $\mathrm{GHz}$ was also simulated.
\end{abstract}

Keywords: High gain, directional, small intestine, low-UWB band, multi-layer model, WCE.

\section{INTRODUCTION}

In recent years UWB directive antennas have been in demand for applications in radar, sensing, and telemetry systems. UWB have also been of interest in the area of Wireless Capsule Endoscopy (WCE) in particular when investigating its use in clinical studies of the small-intestine, a component of the Gastrointestinal (GI) tract [1-2].

In the context of WCE, using UWB band [3.1-10.6 GHz] has the advantage of providing high resolution, in the order of millimeters, and low power consumption in contrast with the use of narrow-band systems [3]. On the other hand, the use of higher frequencies in on-/in body communications incur large path loses. Thus the goal to use as low UWB band as possible for WCE localization purposes [4-5] to minimize path loses and obtain high image resolutions [5].

Several published papers emphasize the importance to comply with the LowUWB band IEEE 802.15.6 standard [6-7]. Therefore a number of implantable antennas working in the 3.4-4.8 GHz range have been implemented [5], [8-10]. An UWB trapezoid monopole antenna [11], a broadband horn antenna [5], a planar unbalanced 
dipole antenna [12], and a helical receiving antenna [13] have been used as receiving antenna for tests and measurement in WCE localization scenarios using different frequency ranges.

In this paper an UWB antenna operating in the Low-UWB band of the IEEE 802.15.6 standard is presented. The proposed antenna is directional and provides high gain. A comparative study of published UWB antennas is found in [14] confirming that the proposed antenna has a very good performance and that is a good candidate as a receiving for WCE localization systems. The detailed antenna structure is described in Section II. Antenna configuration, analysis and discussion are provided in section III. Conclusions and future work are included in Section IV.

\section{$2 \quad$ Antenna structure}

\subsection{Antenna design}

The proposed antenna is a dipole type of antenna. The structure is printed on a FR-4 material with $1.6 \mathrm{~mm}$ thickness (hs), $30 \mathrm{~mm}$ width (Ws), and $25 \mathrm{~mm}$ in length (Ls). Let $\lambda\left(\frac{c}{f}\right)$ be the wavelength at $4 \mathrm{GHz}$ (center frequency of the IEEE 802.15.6 Low UWB band). The antenna size then corresponds to $0.41 \lambda \times 0.33 \lambda \times 0.021 \lambda$. The ground plane is a combination of a rectangle and an inverted-L form, while the radiator element has a close inverted-L shape. The antenna structure is fed by a microstrip line of $3 \mathrm{~mm}$ width. Front and back sides of the proposed UWB antenna geometry are depicted in Fig. 1. Optimized parameters of the proposed Low-UWB antenna are summarized in Table 1.

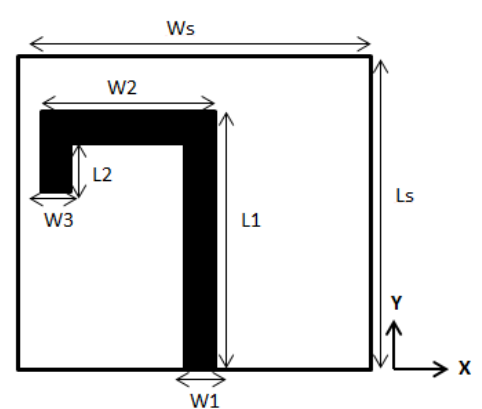

(a)

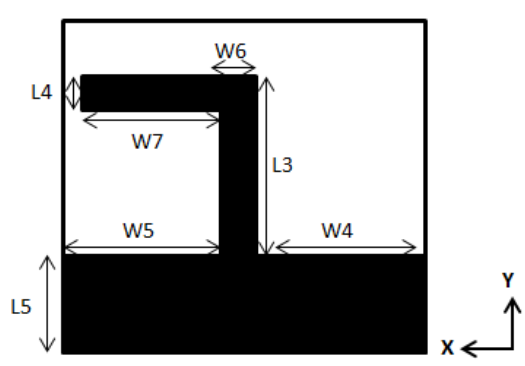

(b)

Fig. 1. Geometry of the proposed Low-UWB band antenna. (a) Front side (b) Back side.

Table 1. OPTIMIZED PARAMETERS OF THE PROPOSED LOW UWB ANTENNA

\begin{tabular}{lllllllll}
\hline Parameter & Ws & Ls & hs & W1 & W2 & W3 & W4 & W5 \\
\hline Value $(\mathrm{mm})$ & 30.3 & 25 & 1.6 & 3 & 16.4 & 3 & 13.15 & 13.15 \\
\hline Parameter & W6 & W7 & L1 & L2 & L3 & L4 & L5 & \\
\hline
\end{tabular}




\begin{tabular}{llllllll}
\hline Value $(\mathrm{mm})$ & 4 & 9.5 & 20.14 & 2.9 & 12 & 2 & 7.14 \\
\hline
\end{tabular}

\section{$3 \quad$ Antenna configuration and analysis}

\subsection{Single Low-UWB antenna}

Every parameter affects the antenna's impedance and resonant frequency. For the sake of brevity the parametric study here is limited to L2 and W7 tune effects on the antenna frequency response.

The effect of L2's length on the reflection coefficient of the proposed UWB antenna is illustrated in Fig. 2 (a). Varying L2 values from 1.5 to $4.5 \mathrm{~mm}$ resulted in a significant shift in the bandwidth and in the resonant frequency in the Low-UWB band. The optimal L2 value that complies with the IEEE 802.15.6 standard is chosen to be $2.9 \mathrm{~mm}$. By using this value, the covered bandwidth is $[3.74-4.25 \mathrm{GHz}]$ and the achieved resonant frequency is $3.906 \mathrm{GHz}$ with maximum reflection coefficient of about $-17.16 \mathrm{~dB}$. For the case when the length of $\mathrm{L} 2$ is increased to $4.5 \mathrm{~mm}$, the bandwidth shifts to the left [3.63-4.12 GHz] and the achieved resonant frequency is at $3.789 \mathrm{GHz}$ with the reflection coefficient of $-17.39 \mathrm{~dB}$. When $\mathrm{L} 2$ is set to $1.5 \mathrm{~mm}$, the bandwidth shifts to the right [3.8-4.37 GHz] and the achieved resonant frequency is at 4.014 GHz with the reflection coefficient of $-19.32 \mathrm{~dB}$.

The effect of W7's length on the reflection coefficient of the proposed antenna by is illustrated in Fig. 2 (b). Varying W7 values from 9.5 to $10.5 \mathrm{~mm}$ with a step of $0.5 \mathrm{~mm}$ reveals that the lower frequency remains quite constant, while increasing W7 leads to a decrease of the upper frequency which degrade significantly the resonant frequency and the maximum reflection coefficient from 3.906 to $3.8 \mathrm{GHz}$ and from 17.16 to $-13.33 \mathrm{~dB}$, respectively.

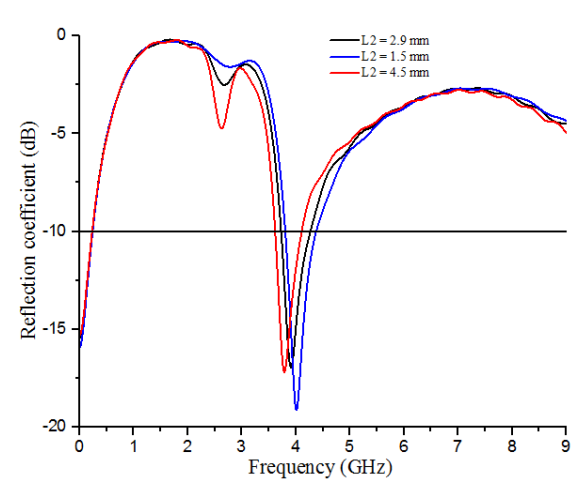

(a)

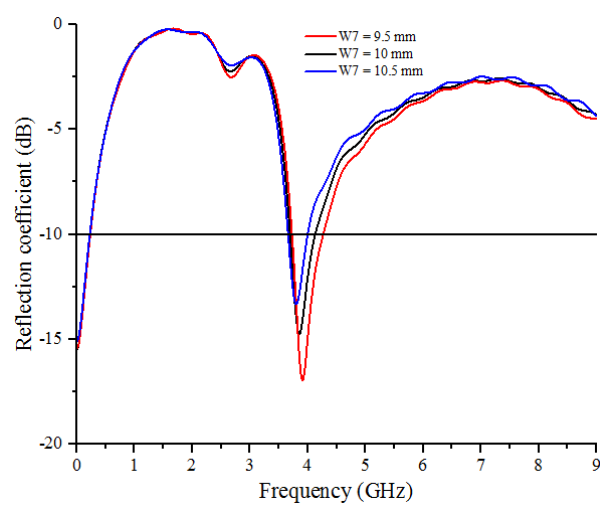

(b)

Fig. 2. Reflection coefficient of the proposed single UWB antenna (a) by varying L2 (b) by varying $\mathrm{W} 7$. 
The input impedance of the proposed Low-UWB single antenna is shown in Fig. 3 (a). At $4 \mathrm{GHz}$, the real part of the parameter $\mathrm{Z} 11$ is $49.22 \Omega \simeq 50 \Omega$ and the imaginary part is about $9.93 \Omega$. It can be then concluded that the proposed antenna has an inductive behavior at $4 \mathrm{GHz}$ center frequency. Besides, these results show that the antenna has a good impedance matching of about $50 \Omega$.

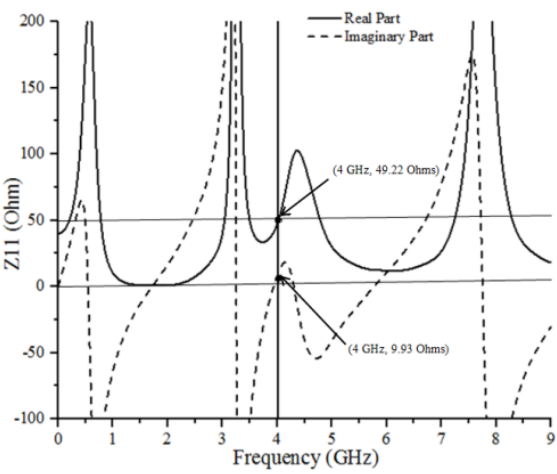

(a)

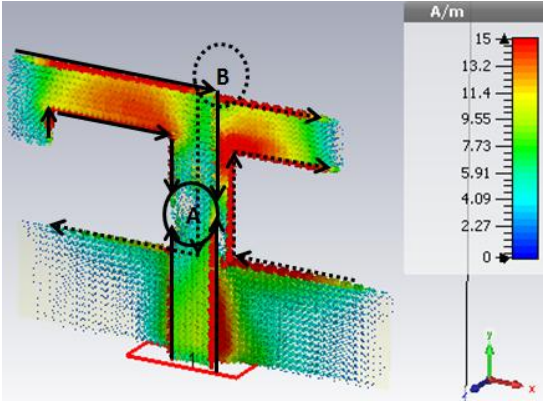

(b)

Fig. 3. (a) Input impedance and (b) Surface current distribution of the single Low-UWB antenna at $4 \mathrm{GHz}$ (Solid arrow: Front side, dashed arrow: Back side).

The surface current distribution of the Low-UWB antenna at $4 \mathrm{GHz}$ is illustrated in Fig. 3 (b). Current directions in the front and back sides are represented by solid and dashed arrows, respectively. It is clearly seen on this illustration that, currents are cancelling each other at part A while at part B currents are moving in opposite directions.

Directivity results of the proposed single Low-UWB antenna at the frequencies $3.74 \mathrm{GHz}, 4 \mathrm{GHz}$ and $4.26 \mathrm{GHz}$ are shown in Fig. 4. These results show that, the single antenna is directive toward $\mathrm{Y}$-axis. At the three frequencies, total and radiation efficiencies are less than $1 \mathrm{~dB}$, which implies a good operation of the proposed antenna. Additionnaly, it is worth noting that, directivity achieves high values up to 6.18 , 6.04 and $5.52 \mathrm{dBi}$ at the frequencies $3.74,4$ and $4.26 \mathrm{GHz}$, respectively.

Radiation patterns of the single Low-UWB antenna at 3.74, 4 and $4.26 \mathrm{GHz}$ are plotted in Fig. 5. Gain values, by cutting axis plans at Theta $=90^{\circ}$, $\mathrm{Phi}=90^{\circ}$ and $\mathrm{Phi}=0^{\circ}$, are summarized in Table. 2 . It is clearly shown that, with the frequency increase from 3.74 to $4.26 \mathrm{GHz}$, the directivity decreases slightly to reach 6.18 and $5.52 \mathrm{dBi}$, respectively. However, maximum directivity is always toward $\mathrm{Y}$ axis $\left(\right.$ Theta $\left.=90^{\circ}\right)$. 


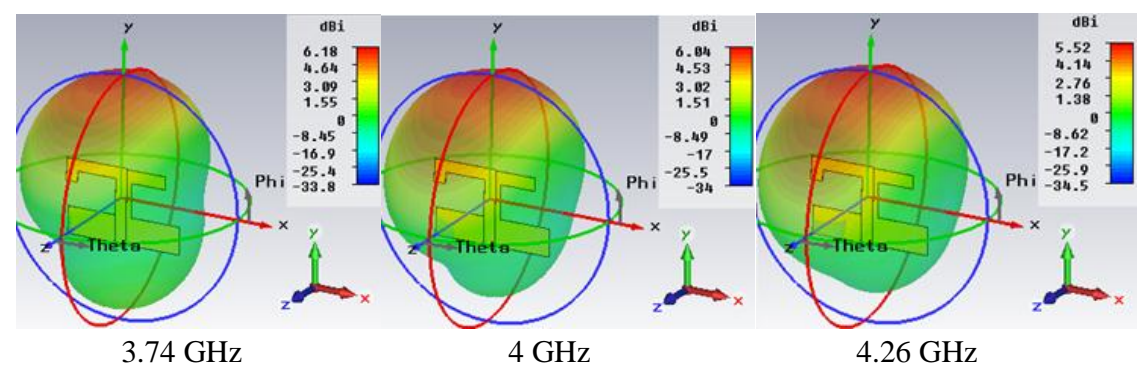

Fig. 4. Directivity of the single Low-UWB antenna with the hidden substrate at $3.74 \mathrm{GHz}$, $4 \mathrm{GHz}$ and $4.26 \mathrm{GHz}$.
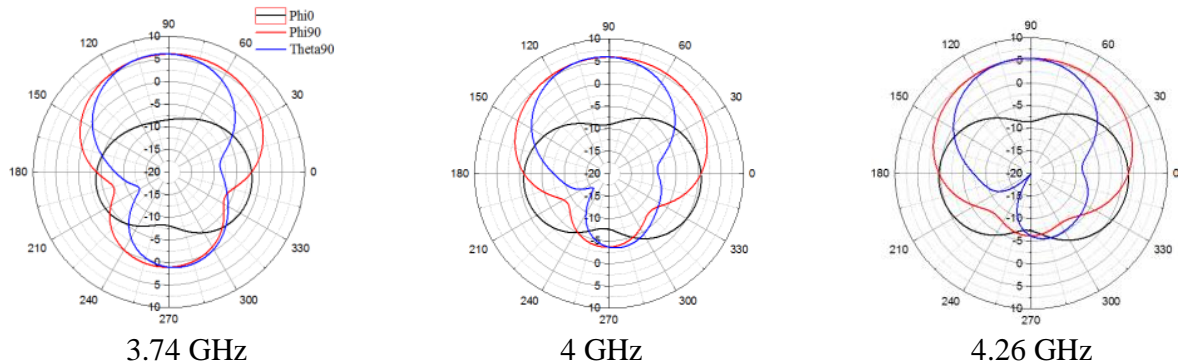

Fig. 5. Radiation patterns of the single Low-UWB antenna at $3.74 \mathrm{GHz}, 4 \mathrm{GHz}$ and $4.26 \mathrm{GHz}$ $\left(\right.$ Black $=>$ Phi $=0^{\circ}$, Red $=>P h i=90^{\circ}$ and Blue $=>$ Theta $\left.=90^{\circ}\right)$.

Table 2. GAIN VALUES OF THE PROPOSED SINGLE LOW-UWB ANTENNA BY CUTTING AXIS PLANS

\begin{tabular}{llll}
\hline Frequency $[\mathrm{GHz}]$ & Theta $=90^{\circ}[\mathrm{dBi}]$ & $\mathrm{Phi}=90^{\circ}[\mathrm{dBi}]$ & $\mathrm{Phi}=0^{\circ}[\mathrm{dBi}]$ \\
\hline 3.74 & 6.17 & 6.14 & -1.46 \\
4 & 6.04 & 5.99 & 0.674 \\
4.26 & 5.52 & 5.46 & 1.51 \\
\hline
\end{tabular}

\subsection{Cavity approach}

In this second part, a metallic box serving as a cavity with a thickness of $0.5 \mathrm{~mm}$ is used. The cavity approach is used to act as a reflector ensuring good directivity and high gain improvement [15-16]. The single antenna is positioned in the cavity center. The cavity size is $90.8 \times 85 \times 39.5 \mathrm{~mm}^{3}$ which corresponds to $1.21 \lambda \times 1.13 \lambda \times 0.52 \lambda$ ( $\lambda$ is the wavelength at $4 \mathrm{GHz}$ ). The overall configuration of the proposed cavitybacked Low-UWB antenna is illustrated in Fig. 6 (a). 


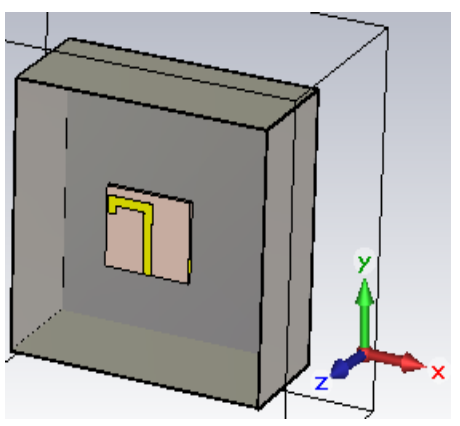

(a)

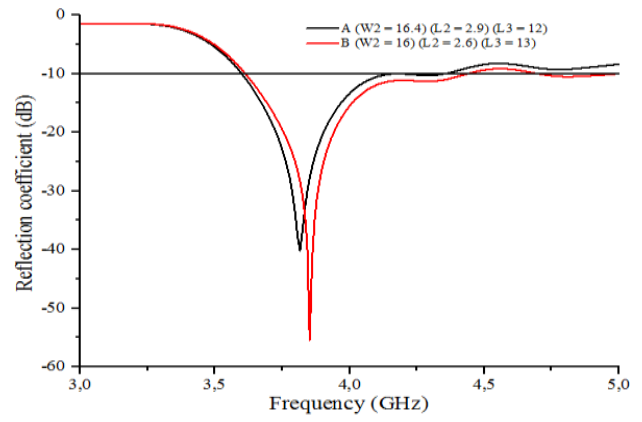

(b)

Fig. 6. (a) Overall view of the cavity-backed Low-UWB antenna. (b) Reflection coefficient of the cavity-backed Low-UWB antenna by tuning W2, L2 and L3 parameters.

Antenna parameter values are reviewed when introducing the cavity. The most influencing parameters are W2, L2 and L3, the antenna is more sensitive to these parameters. Fig. 6 (b) shows the reflection coefficient of the single antenna inserted within the cavity (case A). However, tuning slightly the previously mentioned parameters adapt well the antenna to improve its performance (case B).

Input impedance matching of the proposed cavity-backed Low-UWB antenna at the resonant frequency of $3.85 \mathrm{GHz}$ is presented in Fig. 7 (a) real part of the parameter $\mathrm{Z} 11$ is $55.1 \Omega$ and the imaginary part is about $-0.1 \Omega \simeq 0 \Omega$. It can be concluded from this input impedance study that the proposed antenna has a good impedance matching around $50 \Omega$.

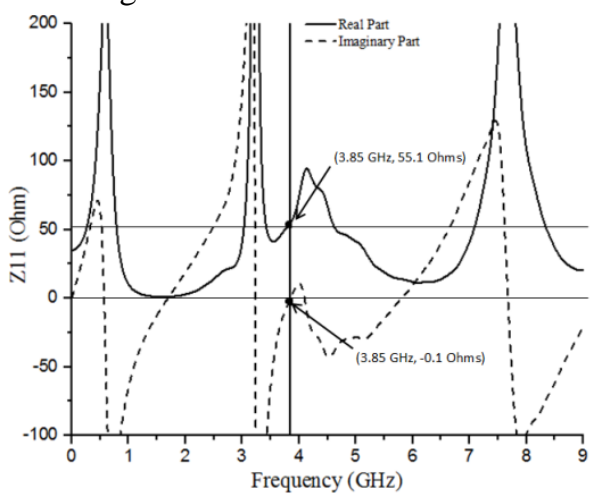

(a)

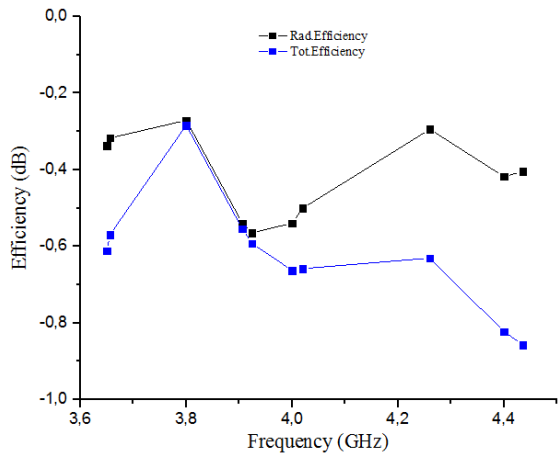

(b)

Fig. 7. (a) Input impedance of the cavity-backed Low-UWB antenna at Fr=3.85 GHz. (b) Radiation and Total efficiency of the cavity-backed Low-UWB antenna over the desired bandwidth.

Radiation and total efficiency of the cavity-backed Low-UWB antenna over the covered bandwidth is less than $-1 \mathrm{~dB}$ as presented in Fig. 7 (b). Therefore, the antenna seems to operate well at Low-UWB band which shows its conformity with IEEE 802.15.6 standard. 
Directivity results of the cavity-backed Low-UWB antenna at the frequencies $3.63 \mathrm{GHz}, 4 \mathrm{GHz}$ and $4.43 \mathrm{GHz}$ are given in Fig. 8. These results show that, the single antenna is directive toward $\mathrm{Z}$-axis. At the three frequencies, total and radiation efficiencies are between -1 and $0 \mathrm{~dB}$, which implies the good operation of the proposed cavity-backed antenna. Additionnaly, it is worth noting that, directivity achieves high values up to $9,8.98$ and $8.41 \mathrm{dBi}$ at the frequencies $3.63,4$ and $4.43 \mathrm{GHz}$, respectively.

Radiation patterns of the single Low-UWB antenna at $3.63,4$ and $4.43 \mathrm{GHz}$ are plotted in Fig. 9. Gain values, by cutting axis plans at Theta $=90^{\circ}$, Phi $=90^{\circ}$ and $\mathrm{Phi}=0^{\circ}$, are summarized in Table. 3 . It is worth nothing that, the directivity decreases from 9 to $8.41 \mathrm{dBi}$ with the increase of frequency from 3.63 to $4.43 \mathrm{GHz}$. However, maximum directivity is always toward $\mathrm{Z}$-axis $\left(\mathrm{Phi}=90^{\circ}\right)$. It is concluded that, the cavity approach comes as a solution to change antenna directivity from $\mathrm{Y}$-axis to closely Z-axis. The cavity approach has proved a significant increase of the maximum gain from 6.04 to $8.98 \mathrm{dBi}$ at $4 \mathrm{GHz}$. Therefore, the aim of this approach for Wireless Capsule Endoscopy localization is to reinforce the radiation to Z-axis and hence to direct the field to the body so the penetration is better with lower power.

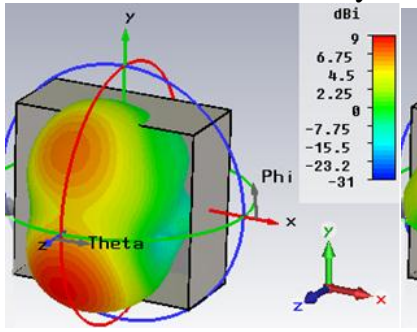

(a)

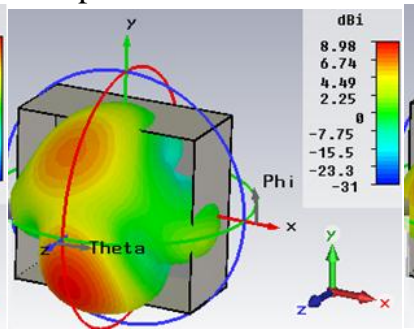

(b)

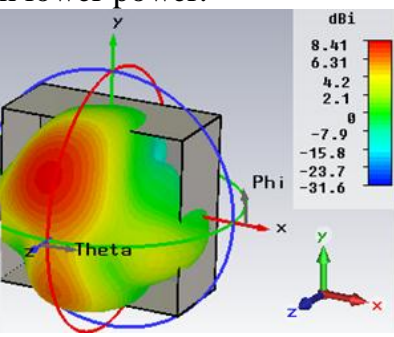

(c)

Fig. 8. Directivity of the cavity-backed Low-UWB single antenna at (a) $3.63 \mathrm{GHz}$, (b) $4 \mathrm{GHz}$ and (c) $4.43 \mathrm{GHz}$.

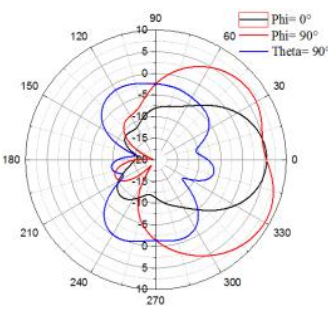

$3.63 \mathrm{GHz}$

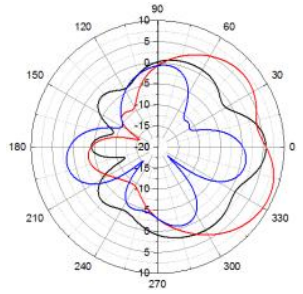

$4 \mathrm{GHz}$

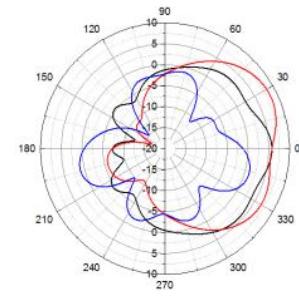

$4.43 \mathrm{GHz}$

Fig. 9. Radiation patterns of the cavity-backed Low-UWB antenna at (a) $3.63 \mathrm{GHz}$, (b) $4 \mathrm{GHz}$ and (c) $4.43 \mathrm{GHz}$. (Black $=>\mathrm{Phi}=0^{\circ}$, Red $=>\mathrm{Phi}=90^{\circ}$ and Blue $=>$ Theta $=90^{\circ}$ ).

Table 3. GAIN VALUES OF THE PROPOSED CAVITY-BACKED LOW-UWB ANTENNA BY CUTTING AXIS PLANS

\begin{tabular}{llll}
\hline Frequency $[\mathrm{GHz}]$ & Theta $=90^{\circ}[\mathrm{dBi}]$ & $\mathrm{Phi}=90^{\circ}[\mathrm{dBi}]$ & $\mathrm{Phi}=0^{\circ}[\mathrm{dBi}]$ \\
\hline 3.6558 & 0.072 & 8.95 & 5.57
\end{tabular}




\begin{tabular}{llll}
3.906 & 0.751 & 9.32 & 6.86 \\
4 & 1.89 & 8.93 & 5.83 \\
4.4361 & 1.12 & 8.39 & 5.7 \\
\hline
\end{tabular}

\subsection{On-Body simulation results}

The performance of a cavity-backed Low-UWB antenna in the vicinity of a human body is investigated in this section as illustrated in Fig. 10 (a). Since WCE localization is important within the small-intestine part of GI tract, for simplicity and as a preliminary realistic study, multi layers in close proximity of the proposed antenna are placed and introduced to emulate dielectric properties of the skin, fat, muscle and small-intestine at $4 \mathrm{GHz}$. The layer arrangement with the associated thickness is as followed: Skin $(2.3 \mathrm{~mm})$, fat 1 (11 $\mathrm{mm}$ for males and $18 \mathrm{~mm}$ for females), muscle (2.7 $\mathrm{mm}$ for males and $4.3 \mathrm{~mm}$ for females), fat $2(10 \mathrm{~mm}$ for males and $30 \mathrm{~mm}$ for females) and small-intestine (2 $\mathrm{mm})$ [17][18]. The dielectric properties of the human tissues at $4 \mathrm{GHz}$ are presented in Table 4 [19-20].

In the literature, for example in [21], the distance between the receiving antenna and the human model is $5 \mathrm{~cm}$. In this study case, the simplified layer is placed at $3 \mathrm{~cm}$ from the proposed cavity-backed Low-UWB antenna.

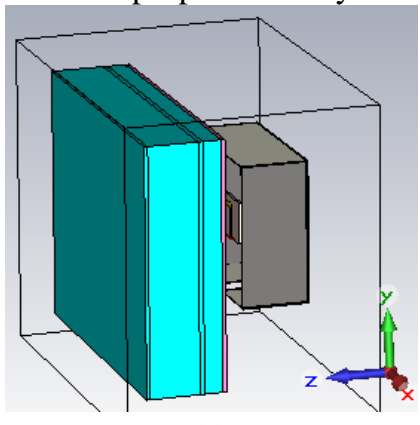

(a)

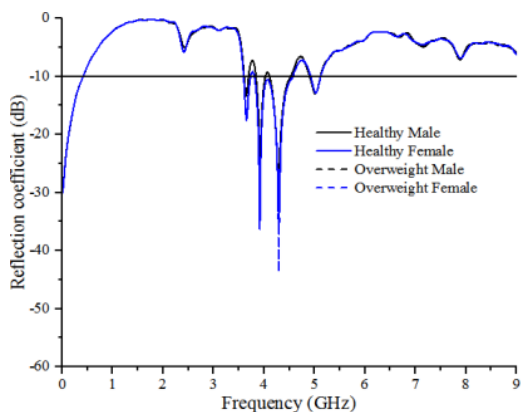

(b)

Fig. 10. (a) Cavity-backed Low-UWB antenna in close proximity to the human model. (b) Comparison of reflection coefficient with different study cases.

A comparison study based on the reflection coefficient of the proposed cavitybacked antenna in proximity to human model is shown in Fig. 10 (b). The study cases distinguish between healthy and overweight persons by selecting the gender (male and female).The introduction of the multi-layer model in vicinity to the proposed cavity-backed antenna assure a bandwidth around [3.62-4.55 GHz], for all the study cases, which covers the required bandwidth [3.75-4.25 GHz] for Low-UWB band of IEEE 802.15.6 standard for Body Area Network (BAN). However, it is clearly seen from the results presented in Table 5 that maximum reflection coefficient for overweight persons is higher that for healthy persons. Furthermore, the maximum reflection coefficient for female tissues is higher than for male tissues. The resonant 
frequency is around $4.27 \mathrm{GHz}$ for different human tissues. From Table 5, it is concluded that the proposed cavity-backed Low-UWB antenna is suitable to WCE purposes and conforms well with the IEEE 802.15.6 standard.

Table 4. DIELECTRIC PROPERTIES OF HUMAN TISSUES AT 4 GHZ

\begin{tabular}{cccc}
\hline Tissue Layer & Permittivity & Conductivity $(\mathrm{S} / \mathrm{m})$ & Tang Loss \\
\hline Small Intestine & 51.7 & 4.62 & 0.402 \\
Muscle & 50.8 & 3.01 & 0.267 \\
Fat & 5.13 & 0.183 & 0.16 \\
Skin & 36.6 & 2.34 & 0.287 \\
\hline
\end{tabular}

Table 5. ANTENNA PERFORMANCE PER STUDY CASE

\begin{tabular}{cccc}
\hline Study Case & Fr & BW & S11|Fr \\
\hline Healthy Male & $4.28 \mathrm{GHz}$ & {$[3.62-4.52 \mathrm{GHz}]$} & $-26.71 \mathrm{~dB}$ \\
Healthy Female & $4.29 \mathrm{GHz}$ & {$[3.62-4.55 \mathrm{GHz}]$} & $-36.97 \mathrm{~dB}$ \\
Overweight Female & $4.29 \mathrm{GHz}$ & {$[3.6-4.59 \mathrm{GHz}]$} & $-43.75 \mathrm{~dB}$ \\
Overweight Male & $4.29 \mathrm{GHz}$ & {$[3.6-4.55 \mathrm{GHz}]$} & $-27.54 \mathrm{~dB}$ \\
\hline
\end{tabular}

Radiation patterns of the single Low-UWB antenna at $3.57,4$ and $4.43 \mathrm{GHz}$ in vicinity to human tissues are plotted in Fig. 11. Gain values, by cutting axis plans at Theta $=90^{\circ}$, Phi $=90^{\circ}$ and $\mathrm{Phi}=0^{\circ}$, are summarized in Table. 5. Results show that high gain is still maintained even in close proximity to different human tissues (multi layers model). However, maximum gain is slightly decreased for overweight person cases. It is clearly seen that, different human tissues features (gender, thickness) do not affect too much the resulted radiation pattern.

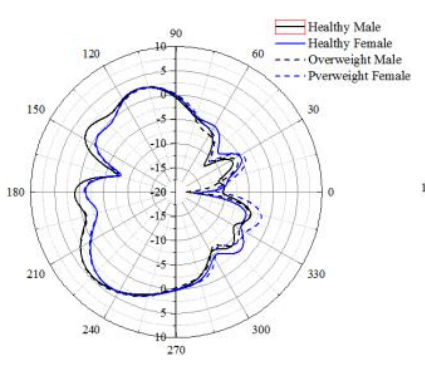

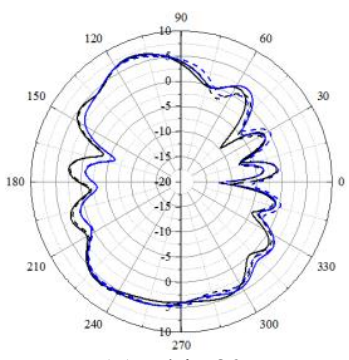

(a) $\mathrm{Phi}=0^{\circ}$

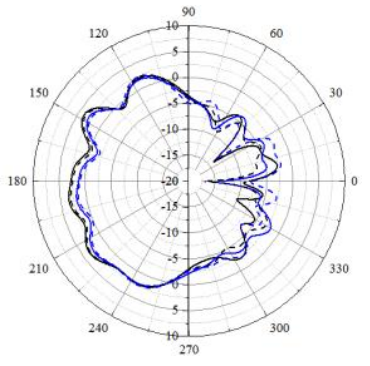



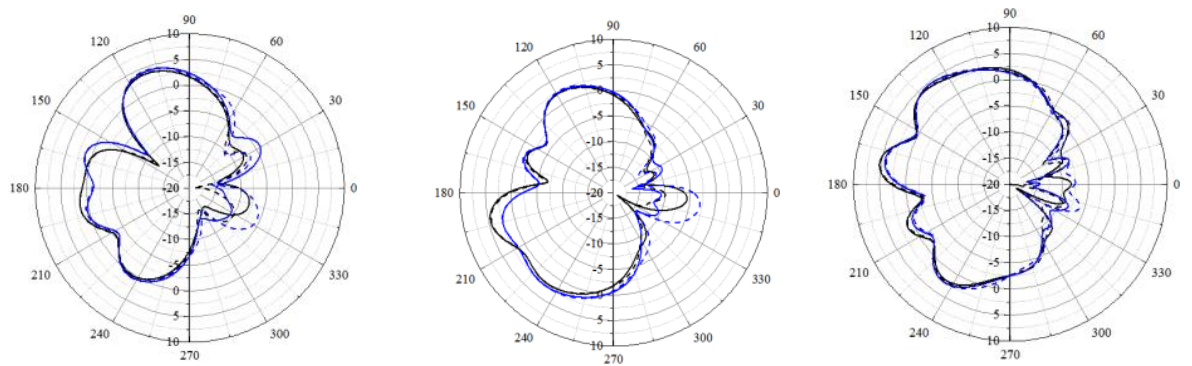

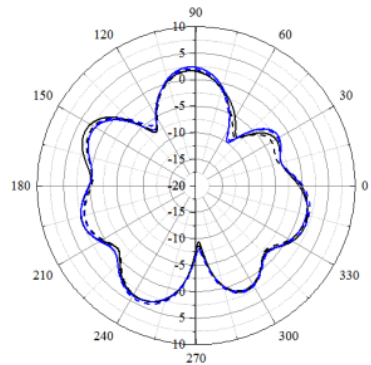

$3.5757 \mathrm{GHz}$ (b) $\mathrm{Phi}=90^{\circ}$

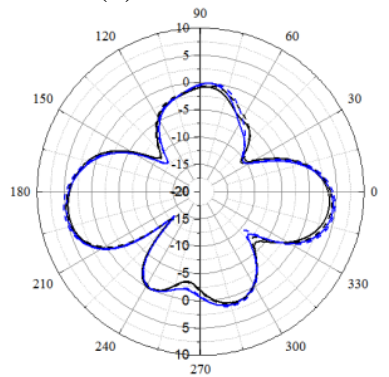

(c) Theta $=90^{\circ}$ $4 \mathrm{GHz}$

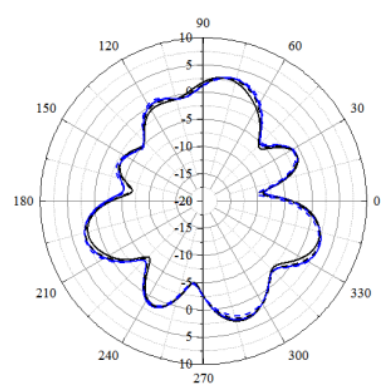

$4.4361 \mathrm{GHz}$

Fig. 11. Radiation patterns of the cavity-backed Low-UWB antenna at $3.57 \mathrm{GHz}, 4 \mathrm{GHz}$ and 4.43 GHz. (a) $\mathrm{Phi}=0^{\circ}$, (b) $\mathrm{Phi}=90^{\circ}$ and (c) Theta $=90^{\circ}$ (Black solid $=>$ Healthy Male, Blue solid=>Healthy Female, Black dashed=>Overweight Male and Blue dashed=>Overweight Female).

Table 6. GAIN VALUES OF THE PROPOSED CAVITY-BACKED LOW-UWB ANTENNA IN CIVINITY TO HUMAN MODEL LAYERS BY CUTTING AXIS PLANS

\begin{tabular}{|c|c|c|c|c|}
\hline Study Case & Frequency [GHz] & Theta $=90^{\circ}[\mathrm{dBi}]$ & $\mathrm{Phi}=90^{\circ}[\mathrm{dBi}]$ & $\mathrm{Phi}=0^{\circ}[\mathrm{dBi}]$ \\
\hline \multirow{3}{*}{ Healthy Male } & 3.5757 & 3.82 & 3.78 & 4.51 \\
\hline & 4 & 4.53 & 4.63 & 6.81 \\
\hline & 4.4361 & 3.06 & 5.32 & 3.89 \\
\hline \multirow{3}{*}{ Healthy Female } & 3.5757 & 3.92 & 4.24 & 3.9 \\
\hline & 4 & 4.89 & 2.53 & 6.63 \\
\hline & 4.4361 & 3.19 & 4.57 & 2.87 \\
\hline \multirow{3}{*}{ Overweight Female } & 3.5757 & 4.33 & 4.43 & 3.99 \\
\hline & 4 & 5.32 & 2.58 & 6.38 \\
\hline & 4.4361 & 3.18 & 4.59 & 2.51 \\
\hline \multirow{3}{*}{ Overweight Male } & 3.5757 & 3.84 & 3.88 & 4.67 \\
\hline & 4 & 4.83 & 4.47 & 6.53 \\
\hline & 4.4361 & 2.97 & 5.21 & 3.54 \\
\hline
\end{tabular}




\section{Conclusion and perspectives}

A new Low-UWB band directive antenna for WCE localization systems is presented in this paper. Good directivity is achieved for both single antenna and cavitybacked antenna. Furthermore, they both comply with IEEE 802.15.6 standard requirements. For the single antenna, the gain reaches a value of $6.14 \mathrm{dBi}$ at $4 \mathrm{GHz}$. For the proposed cavity-backed antenna, the gain is increased to $8.93 \mathrm{dBi}$ at $4 \mathrm{GHz}$. The work was not restricted to free space investigations, but also an on-body preliminary realistic study was carried out. For this end, a multi-layer model emulating dielectric properties of the different human tissues at $4 \mathrm{GHz}$ was used and satisfying results are concluded. According to the presented simulated results, it is concluded that both single antenna and cavity-backed antenna provide satisfying results for WCE localization purposes. Fabrication, measured results and necessary tests using phantoms and realistic scenarios will be presented in the future work to validate these simulated results.

\section{References}

1. H. Neumann; Luc1a. C. Fry; A. Nagel; and M. F. Neurath, "Wireless capsule endoscopy of the small intestine: a review with future directions", Current Opinion in Gastroenterology, vol. 30, pp. 463-471, 2014.

2. W. Chen; G. Yan; Z. Wang; P. Jiang; H. Liu, "A wireless capsule robot with spiral legs for human Intestine", The International Journal of Medical Robotics and Computer Assisted Surgery, vol. 10, pp. 147-161, 2013.

3. K. Y. Yazdandoost; K. Takizawa; R. Miura, "UWB Antenna and Propagation for Wireless Endoscopy", 2014 IEEE 25th Annual International Symposium on Personal, Indoor, and Mobile Radio Communication (PIMRC), pp. 2155 - 2159, 2014.

4. J. Shi; J. Wang, "Channel Characterization and Diversity Feasibility for In-Body to OnBody Communication using Low-band UWB Signals", 3rd International Symposium on Applied Sciences in Biomedical and Communication Technologies (ISABEL 2010), pp. 14, 2010.

5. K. M. S. Thotahewa; J. -M. Redoutè; M. R. Yuce, "Propagation, Power Absorption, and Temperature Analysis of UWB Wireless Capsule Endoscopy Devices Operating in the Human Body", IEEE Transactions on Microwave Theory and Techniques, vol. 63, pp. $3823-3833,2015$.

6. R. C-. Santiago; K. S-. Pour; A. Khaleghi; K. Takizawa; J. Wang; I. Balasingham; H.-B. $\mathrm{Li}$, "Propagation Models for IEEE 802.15.6 Standardization of Implant Communication in Body Area Networks", IEEE Communications Magazine, vol. 51, pp. 80 - 87, 2013.

7. IEEE Standard for Local and metropolitan area networks_Part 15.6: Wireless Body Area Networks, pp. IEEE Std 802.15.6-2012, pp. 1 - 271, 2012.

8. K. M. S. Thotahewa; J. -M. Redouté; M. R. Yuce, "Electromagnetic Power Absorption of the Human Abdomen from IR-UWB Based Wireless Capsule Endoscopy Devices", IEEE International Conference on Ultra-Wideband (ICUWB), pp. 79-84, 2013.

9. D. Anzai; K. Katsu; R. C. -Santiago; Q. Wang; D. Plettemeier; J. Wang; I. Balasingham, "Experimental Evaluation of Implant UWB-IR Transmission With Living Animal for Body Area Networks", IEEE Transactions on Microwave Theory and Techniques, vol. 62, pp. $183-192,2014$. 
10. M. S. Arefin; J. -M. Redoute; M. R. Yuce, "Meandered Conformal Antenna for ISM-band Ingestible Capsule Communication Systems", 2016 38th Annual International Conference of the IEEE Engineering in Medicine and Biology Society (EMBC), pp. $3031-3034$, 2016.

11. Q. Wang, K. Wolf, and D. Plettemeier, "An uwb capsule endoscope antenna design for biomedical communications," in Applied Sciences in Biomedical and Communication Technologies (ISABEL), 2010 3rd International Symposium on, pp. 1-6, IEEE, 2010.

12. Y. Morimoto, D. Anzai and J. Wang, "Design of ultra wide-band low-band implant antennas for capsule endoscopy application," in Proc. 7th Intl. Symp. On Medical Information and Commun. Technol. (ISMICT), pp. 61-65, 2013.

13. D. Anzai; K. Katsu; R. C. -Santiago; Q. Wang; D. Plettemeier; J. Wang; I. Balasingham, "Experimental Evaluation of Implant UWB-IR Transmission With Living Animal for Body Area Networks", IEEE Transactions on Microwave Theory and Techniques, vol. 62, pp. $183-192,2014$.

14. E. L-. Arzate; J. A. T-. Mendez; J. C-. Franca ; R. F-. Leal ; H. J-. Aguilar; M. A. P-. Solis, "Ultra-wideband directive antenna based on an inclined cone body", IET Microwaves, Antennas \& Propagation, vol. 12, pp. 339-345, 2018.

15. A. Munir; and R. B. V. B. Simorangkir, "Performance enhancement of cavity-backed UWB printed monopole antenna", IEEE Asia Pacific Microwave Conference (APMC), pp. 587-587, 2017.

16. A. Edalati, W. Shao, T. McCollough, and W. McCollough, "A Novel Cavity Backed Monopole Antenna with UWB Unidirectional Radiation", Progress In Electromagnetics Research C, Vol. 72, pp. 1-13, 2017.

17. S.M. Bunce, A.P. Moore, A.D. Hough, "M-mode ultrasound: a reliable measure of transversus abdominis thickness?", Clinical Biomechanics, vol. 17, pp. 315-317, 2002.

18. O. Akkus, A. Oguz, M. Uzunlulu* and M. Kizilgul, "Evaluation of Skin and Subcutaneous Adipose Tissue Thickness for Optimal Insulin Injection”, Diabetes \& Metabolism, pp. 3-8, 2012.

19. http://www.fcc.gov/oet/rfsafety/dielectric.html

20. https://www.itis.ethz.ch/virtual-population/tissue-properties/database/dielectric-properties/

21. Q. Wang, K. Wolf, and D. Plettemeier, "An uwb capsule endoscope antenna design for biomedical communications," in Applied Sciences in Biomedical and Communication Technologies (ISABEL), 2010 3rd International Symposium on, pp. 1-6, IEEE, 2010. 